\title{
Review Article \\ Diverse Functions of Pulmonary Collectins in Host Defense of the Lung
}

\author{
Shigeru Ariki, Chiaki Nishitani, and Yoshio Kuroki \\ Department of Biochemistry, Sapporo Medical University School of Medicine, S1 W17, Chuo-ku, Sapporo 060-8556, Japan
}

Correspondence should be addressed to Shigeru Ariki, sarikscb@sapmed.ac.jp

Received 10 January 2012; Accepted 19 March 2012

Academic Editor: Nobutaka Wakamiya

Copyright () 2012 Shigeru Ariki et al. This is an open access article distributed under the Creative Commons Attribution License, which permits unrestricted use, distribution, and reproduction in any medium, provided the original work is properly cited.

Pulmonary surfactant is a mixture of lipids and proteins that covers alveolar surfaces and keeps alveoli from collapsing. Four specific proteins have been identified in surfactant. Among them, two C-type lectins, surfactant proteins A and D (SP-A and SPD), are known to be implicated in host defense and regulation of inflammatory responses of the lung. These host defense lectins are structurally characterized by N-terminal collagen-like domains and lectin domains and are called pulmonary collectins. They prevent dissemination of infectious microbes by their biological activities including agglutination and growth inhibition. They also promote clearance of microbes by enhancing phagocytosis in macrophages. In addition, they interact with the other patternrecognition molecules, including Toll-like receptors (TLRs) and TLR-associated molecules, CD14 and MD-2, and regulate inflammatory responses. Furthermore, recent studies have demonstrated that these collectins modulate functions of neutrophil-derived innate immune molecules by interacting with them. These findings indicate that pulmonary collectins play critical roles in host defense of the lung.

\section{Introduction}

The respiratory system is always exposed to ambient air that contains significant numbers of infectious microbes. The innate immune system in respiratory mucosa is important as a first line of host defense against microbes. Once patternrecognition receptors sense the microbes, inflammatory responses are triggered immediately [1]. These inflammatory responses should be regulated thoroughly to prevent tissue injury caused by excess inflammation.

The surface of the respiratory tract is covered with pulmonary surfactant which is known for its essential role in reducing surface tension to keep alveoli from collapsing [2]. Pulmonary surfactant is a mixture of lipids (90\%) and proteins $(10 \%)$ that are produced and secreted by alveolar type II cells. The majority of lipids contained in pulmonary surfactant are phospholipids including phosphatidylcholine and phosphatidylglycerol [3]. These phospholipids are important for surfactant functions. For example, dipalmitoyl phosphatidylcholine is essential for lowering surface tension.
Furthermore, a recent study has suggested that phosphatidylglycerol and phosphatidylinositol are involved in regulation of inflammatory responses [4]. Four specific surfactant proteins (SPs), SP-A, SP-B, SP-C, and SP-D, have been identified. Hydrophobic proteins, SP-B and SP-C, are critical for the biophysical functions of surfactant [5]. Hydrophilic proteins, SP-A and SP-D, belong to the C-type lectin superfamily and are called pulmonary collectins. The structure of pulmonary collectins is characterized by four domains that consist of an $\mathrm{N}$-terminus involved in interchain disulfide bonding, a collagen-like domain, a coiled coil neck domain and a lectin, or carbohydrate recognition domain (CRD), which is a lectin domain. Each monomeric protein is assembled to form a triple helix at the collagenous domain. These trimers are further oligomerized to form a bouquet-like octadecamer for SP-A and a cruciform dodecamer for SP-D. A subpopulation of SP-D includes a multimerized oligomer consisting of SP$\mathrm{D}$ molecules associated at their $\mathrm{N}$-terminus (Figure 1) [6]. In this paper, we focus on pulmonary collectins and discuss their roles in innate immune responses of the lung. 

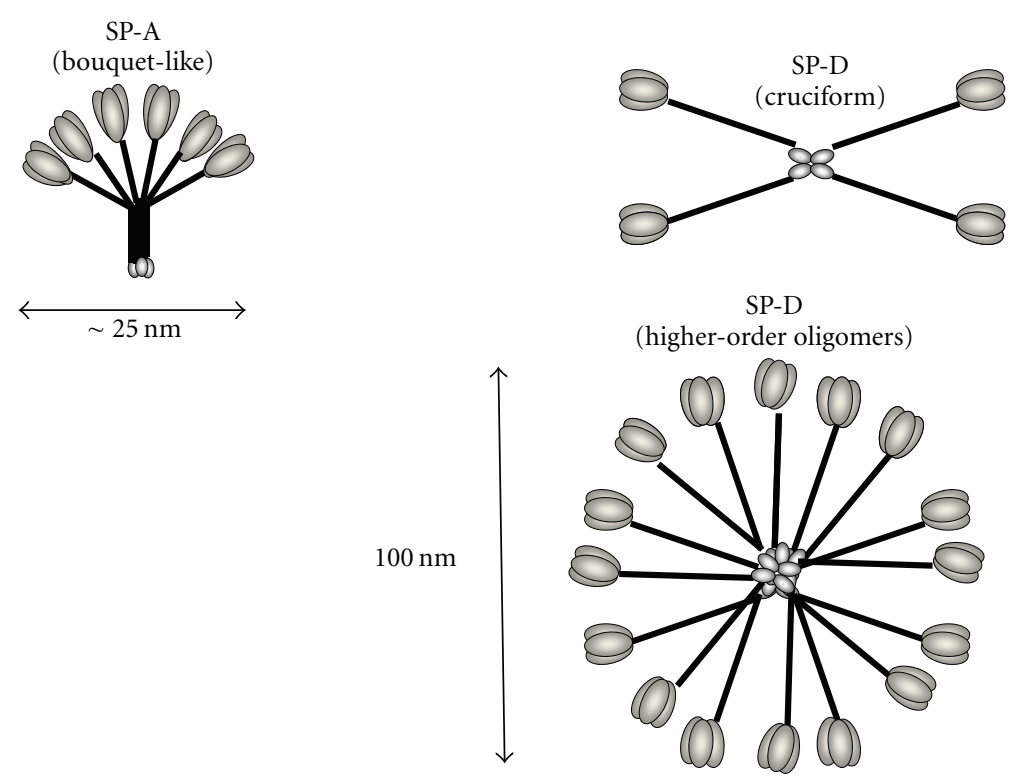

FIGURE 1: Structural organization of pulmonary collectins. SP-A forms a bouquet-like octadecamer assembled from six trimers, while SP-D forms a cruciform dodecamer assembled from four trimers. A subpopulation of SP-D forms a multimerized oligomer associated with their N-termini.

\section{Mouse Model}

Genetic elimination of pulmonary collectins in mice has provided invaluable information regarding their important roles in the innate immunity and maintenance of pulmonary homeostasis. Although the SP-A-deficient mice exhibit no apparent pathological changes [7], $S P$ - $D$-deficient mice show impaired surfactant lipid metabolism that results in advanced alveolar proteinosis [8]. Deficiency of SP-D also causes abnormal pulmonary structure similar to that in emphysema [9]. These knockout mice are susceptible to bacterial and viral infections. Deficiency of pulmonary collectins causes slower clearance of microbes including Pseudomonas aeruginosa [10, 11], Mycoplasma pulmonis [12], Pneumocystis carinii [13], Histoplasma capsulatum [14], Haemophilus influenza [15], group B streptococcus [15, 16], respiratory syncytial virus $[17,18]$, and influenza type A virus $[19,20]$. The knockout mice also exhibit increased inflammation after infection of $P$. aeruginosa, $H$. influenza, group B streptococcus, and influenza type A virus $[10,15,20]$. These observations clearly indicate that pulmonary collectins play critical roles in host defense of the lung. In the following sections, the roles of pulmonary collectins in innate immune system will be described in detail.

\section{Direct Actions of Pulmonary Collectins on Microbes}

Pulmonary collectins directly interact with and agglutinate various microbes including fungi, yeasts, bacteria, and viruses to prevent dissemination. These collectins bind to various ligands existing on the surface of microbes. For example, lipopolysaccharides (LPS) on Gram-negative bacteria, lipoteichoic acid on Gram-positive bacteria, glycoprotein on fungi, lipoarabinomannan on mycobacteria, phospholipids on mycoplasma, and viral surface glycoproteins have been identified as ligands for pulmonary collectins [21]. Among these ligands, the binding of collectins to LPS is well characterized. SP-A binds rough LPS and lipid A but not smooth LPS [22, 23]. SP-D binds Re LPS through the neck domain, and Rc LPS, core oligosaccharide of LPS and selective mannose-rich smooth LPS through the CRD domain $[6,24$, 25]. Analysis of the crystal structure of SP-A reveals an extensive hydrophobic surface, which contributes to differences in binding specificity observed between this protein and SP$\mathrm{D}$ [26]. When binding to Mycobacterium avium, SP-A binds lipid ligand on M. avium containing no saccharide, while SPD binds mannose-rich glycolipid, lipoarabinomannan [27]. These findings suggest that SP-A tends to bind more to hydrophobic ligand than SP-D.

In addition to agglutination activity, pulmonary collectins also exhibit direct inhibitory effects on the growth of some microbes such as Escherichia coli, Klebsiella pneumoniae, Enterobacter aerogenes, Legionella pneumophila, M. avium, H. capsulatum, and Mycoplasma pneumoniae. Incubation of E. coli with pulmonary collectins results in enhanced chromosomal staining with propidium iodide (an impermeant fluorescent dye), indicating that both SP-A and SP-D inhibit the growth of Gram-negative bacteria by increasing membrane permeability [28]. These pulmonary collectins also inhibit the growth of M. avium. Significant effect of growth inhibition was observed when the bacteria were cultured in the presence of SP-A. Different from the case against Gram-negative bacteria, both SP-A and SP-D did not increase the membrane permeability of $M$. avium. When $M$. avium cultured in the presence of pulmonary collectins 
was observed under a scanning electron microscope, the surfaces of the bacteria were covered with proteins. The covered bacteria were more frequently observed in the sample cultured with SP-A. Furthermore, SP-A dramatically decreased nutrient uptake of the bacteria. These data infer that pulmonary collectins inhibit the growth of M. avium by forming a physical barrier around the bacterial surface to restrict nutrient uptake [27].

The growth of Gram-negative bacteria was inhibited by C-terminal fragments of pulmonary collectins, which agglutinated the bacteria very weakly [28]. Furthermore, SP-A strongly inhibited the growth of M. avium in spite of its negligible agglutination activity against the bacteria [27]. Thus, it is likely that agglutination and growth inhibition by pulmonary collectins are independent activities.

\section{Regulation of Phagocytosis by Pulmonary Collectins}

The lung collectins augment the uptake of particles and pathogens by different mechanisms. The first mechanism by which pulmonary collectins augment pathogen uptake is by opsonization. For example, C1q receptor mediates the phagocytosis of SP-A-opsonized Staphylococcus aureus (S. aureus) by monocytes [29]. SP-A-opsonized S. aureus [30] and SP-A-opsonized bacillus Calmette-Guérin (BCG) [31] are ingested by macrophage via SP-R210, which is a specific receptor for SP-A [32]. Pulmonary collectins stimulate phagocytosis of Pseudomonas aeruginosa ( $P$. aeruginosa) by alveolar macrophages $[33,34]$. However, $P$. aeruginosa is likely to escape from phagocytosis. Because $P$. aeruginosa elastase degrades pulmonary collectins [35], $P$. aeruginosa elastase protects against SP-A-mediated opsonization of $P$. aeruginosa by degradation of the SP-A [36].

The next mechanism by which pulmonary collectins augment uptake of pathogens is by upregulating expression of cell surface receptors. SP-A stimulates the phagocytosis of Streptococcus pneumoniae (S. pneumonia) in the presence of EDTA, a condition that prevents SP-A attachment to bacteria. Because SP-A increases cell surface localization of scavenger receptor A (SR-A) of alveolar macrophages in a casein kinase-2-dependent manner, SP-A facilitates the phagocytosis of S. pneumoniae [37]. Pulmonary collectins increase the cell surface localization of mannose receptor (MR) on macrophages, resulting in increased phagocytosis of M. avium [38]. Similarly, SP-A upregulates the cell surface localization of MR and augments the uptake of M. tuberculosis [39].

The lung collectins also augment the uptake of mammalian cells. SP-A increases the phagocytosis of erythrocytes opsonized with IgG and complement by monocyte-derived phagocytosis [40], indicating that SP-A augments FcR- and CR1-activity. Pulmonary collectins enhance the uptake of apoptotic cells by interaction with calreticulin and CD91 [41, 42]. In contrast, pulmonary collectins inhibit phagocytosis of alveolar macrophage through signal inhibitory regulatory protein $\alpha(\operatorname{SIRP} \alpha)[43]$.

\section{Pulmonary Collectins Restrict the Growth of Intracellular Microbes}

As described above, pulmonary collectins upregulate phagocytosis of M. tuberculosis, M. avium, and L. pneumophila. These bacteria are intracellular pathogens that can replicate within macrophages, and it is important to determine whether the effects of the collectins contribute to clearance of microbes, or promote pathogen survival. Recently, Sawada et al. have reported interesting results that resolve this issue (Figure 2) [44]. In the report, intracellular growth of L. pneumophila was significantly inhibited in macrophages infected in the presence of pulmonary collectins. Experiments using the $\mathrm{pH}$-sensitive dye-labeled bacteria revealed that L. pneumophila associated with pulmonary collectins are more efficiently recruited to an acidic intracellular compartment after they are taken up by macrophages. Consistent with these results, L. pneumophila phagocytosed in the presence of collectins showed increased colocalization with LAMP-1 as detected by immunocytochemistry. These data clearly indicate that pulmonary collectins inhibit intracellular growth of L. pneumophila by promoting phagosome-lysosome fusion. Similar results have also been reported by Ferguson et al. using M. tuberculosis and SP-D [45]. Although detailed mechanisms involved in promotion of phagosome-lysosome fusion remain unclear, these data indicate that pulmonary collectins play important roles in eliminating intracellular pathogens.

\section{Pulmonary Collectins Modulate Inflammatory Cellular Responses}

Pulmonary collectins are able to function to enhance or inhibit inflammatory responses depending upon the pathogen, the responding cell, and the cytokine milieu [2, 46, 47]. The molecular mechanisms for collectin engagement of both anti-inflammatory and proinflammatory signaling processes have been investigated. One mode of action of the pulmonary collectins is through direct interactions with pattern recognition receptors, including the Toll-like receptor (TLR) family and the TLR-associated molecule, CD14 and MD-2 (Figure 3). SP-A binds to the extracellular domains of TLR2 and TLR4; MD-2 and CD14 [22, 48-50]. For example, SPA directly interacts with the extracellular TLR2 domain, inhibits the binding of PGN and zymosan to TLR2, and reduces PGN- and zymosan-induced NF- $\kappa \mathrm{B}$ activation and proinflammatory cytokine production [48, 49]. Similarly, SP-A inhibits the binding of smooth LPS to the cell surface of TLR4/MD-2-expressing HEK293 cells [50]. Because SP-A does not directly bind to PGN, zymosan or smooth LPS, the interaction of SP-A with TLR2 or TLR4/MD-2 complex inhibits the recognition of non-SP-A ligands, resulting in the downregulation of their signaling and inflammatory responses. On the other hand, SP-A does not attenuate the inflammatory responses induced by rough LPS, which is an SP-A ligand [22]. Taken together, SP-A modulates the cellular inflammatory responses in a microbial ligand-specific manner (Figure 3). SP-D has been shown to bind to the extracellular domains of TLR2 and TLR4, and to MD-2 


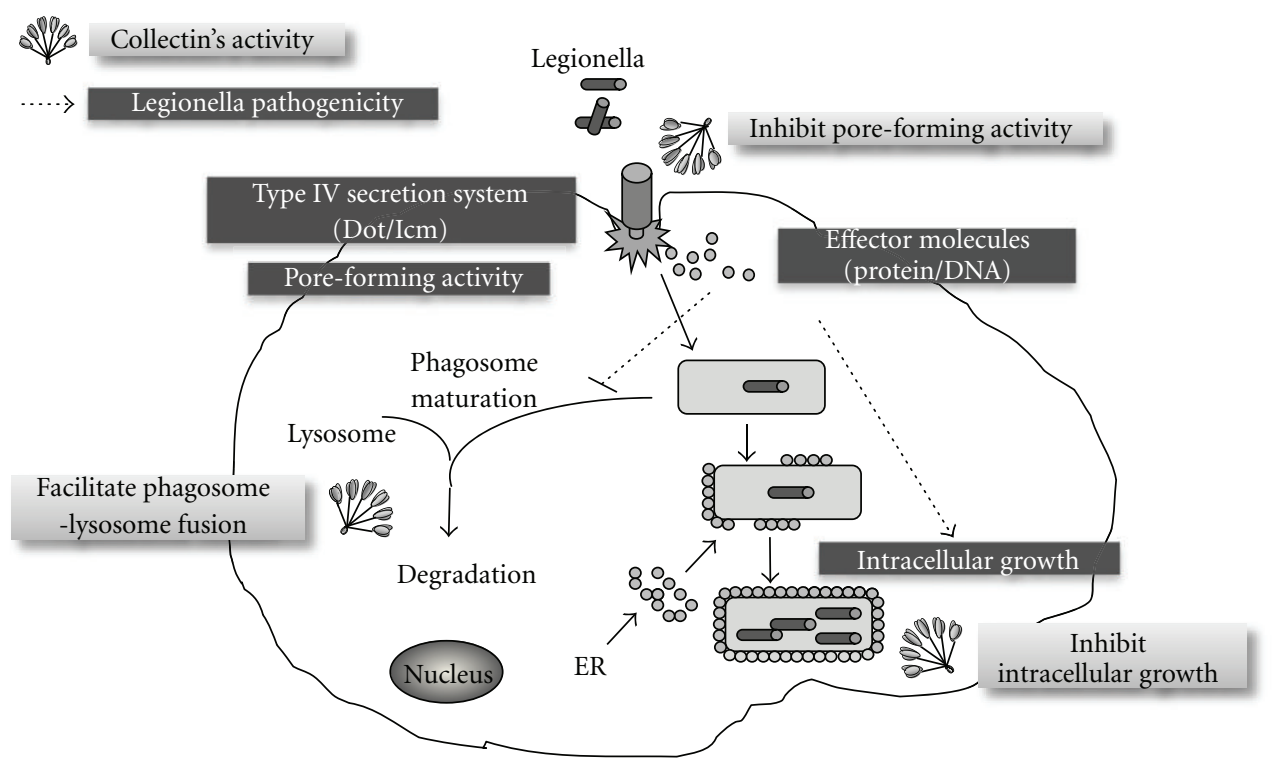

FIGURE 2: Roles of pulmonary collectins in host defense against L. pneumophila. During infection, L. pneumophila secretes various effector molecules via type IV secretion system to manipulate the host cell immune responses. This results in pore-forming on host cell membrane. The secreted effector molecules enable L. pneumophila to bypass phagosomes-lysosome fusion and survive in characteristic vacuoles consisted of ER-derived membrane. Pulmonary collectins protect macrophage membrane against pore-forming activity of L. pneumophila. The collectins also attenuate intracellular growth of L. pneumophila in part by facilitating phagosomes-lysosome fusion.

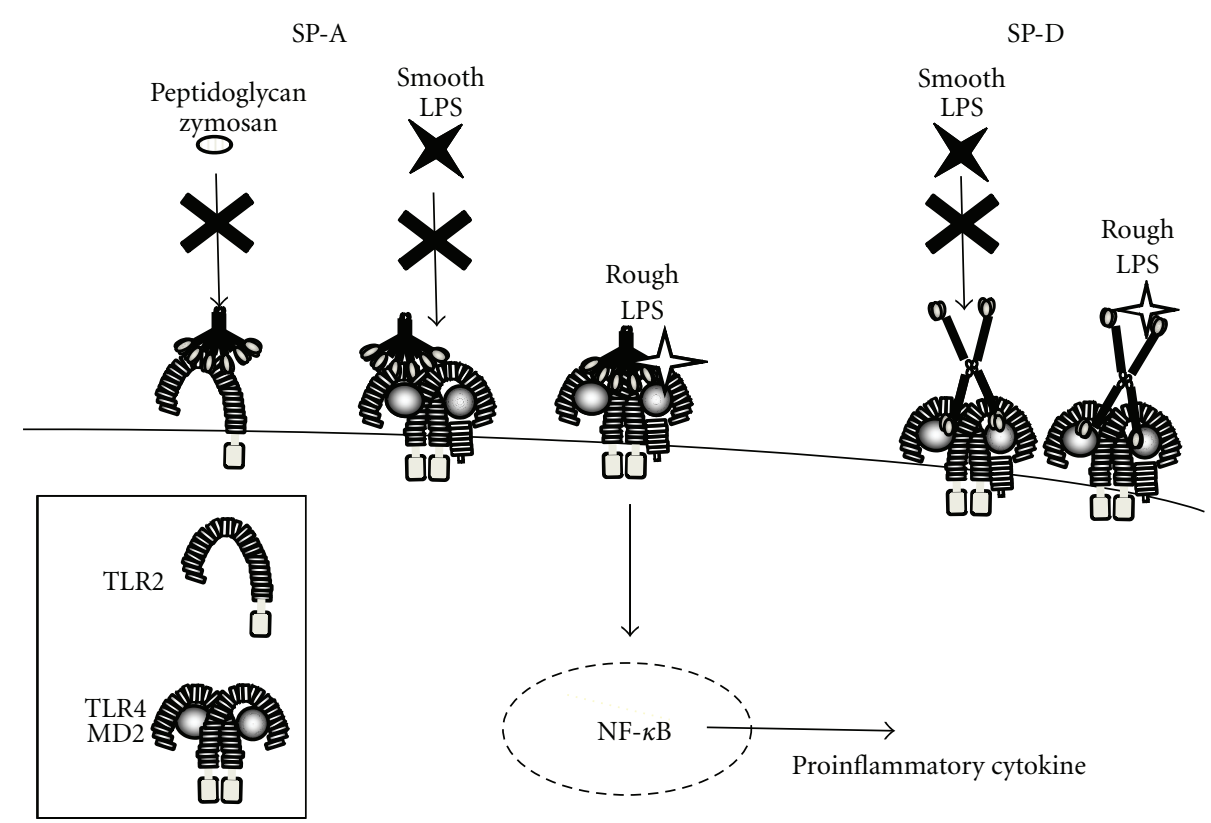

FIgURe 3: Pulmonary collectins modulate inflammation via TLRs. Association of SP-A with TLR2 or TLR4/MD-2 complex results in the downregulation of inflammatory responses by inhibiting the recognition of non-SP-A ligands including smooth LPS, peptidoglycan, and zymosan via TLRs. In contrast, SP-A dose not inhibit secretion of proinflammatory cytokines induced by rough LPS, which is an SP-A ligand. Interaction of SP-D with TLR4/MD-2 complex inhibits proinflammatory cytokine production induced by both smooth and rough LPS.

through its CRD [51-53]. Although rough LPS but not smooth LPS is an SP-D ligand, SP-D inhibits cell surface binding of both serotypes of LPS to TLR4/MD-2-expressing HEK293 cells and attenuates the bindings of the soluble form of MD-2 to LPS. Moreover, SP-D inhibits both serotypes of LPS-induced TNF- $\alpha$ secretion from alveolar macrophages and NF- $\kappa$ B activation in TLR4/MD-2-expressing HEK293 cells. The inhibitory effect of SP-D is dependent upon the formation of cruciform structure and its multimer [53]. Thus, unlike SP-A, SP-D downregulates inflammatory cell 
responses elicited by smooth and rough serotypes of LPS [53] (Figure 3).

Another mechanism of dual functions of pulmonary collectins on inflammation is depending on binding orientation of pulmonary collectins to their receptors [54]. In the absence of microbes, pulmonary collectins bind via their CRD to SIRP $\alpha$ and prevent inflammation. Because the interaction induces the activation of tyrosine phosphatase SHP-1, resulting in blockage of the downstream signaling through src-family kinases and p38 mitogen-activated protein (MAP) kinase [54]. Hence, proinflammatory cytokine production is attenuated by the CRD domain of the pulmonary collectins. In contrast, the collagenous tail of SP-A mediates immunostimulatory effects through binding to calreticulin/CD91 complex. When microbe or cell debris interact with the CRD domain of SP-A, the collagenous domain of SP-A can engage calreticulin/CD91 to stimulate p38 phosphorylation, NF$\kappa \mathrm{B}$ activation, and cytokine production. Calreticulin/CD91 is not only an SP-A receptor but also a receptor for Snitrosylated SP-D (SNO-SP-D) [55]. S-nitrosylation disrupts dodecameric structure of SP-D and bares collagenous tail. The binding of collagenous tail of SNO-SP-D to calreticulin activates p38 phosphorylation, NF- $\kappa \mathrm{B}$ activation and cytokine production [55].

In conclusion, pulmonary collectins modulate inflammatory cellular responses. The distinct effects of pulmonary collectins on inflammation depend on the different binding specificities and orientations against various stimulators and cell surface receptors.

\section{Interaction between Pulmonary Collectins and Other Host Defense Molecules}

In addition to TLRs, MD-2, and CD14, pulmonary collectins interact with additional host defense molecules and modulate innate immune reactions. SP-D has recently been shown to interact with human $\alpha$-defensins 1 and $2[56,57]$. Human $\alpha$-defensins are neutrophil-derived peptides that exhibit wide spectrum antimicrobial activity against bacteria, fungi, and viruses. While human $\alpha$-defensins broadly neutralize multiple strains of influenza A virus, the neutralizing effects of SP$\mathrm{D}$ are dependent on the strain of the virus. SP-D binds to the mannose-rich sugar chain on hemagglutinin and neutralizes virus infectivity. The level of glycosylation on the globular head of hemagglutinin seems to correlate with sensitivity to SP-D [58]. When SP-D-resistant strains were treated with SP$\mathrm{D}$ and $\alpha$-defensin, they exhibited cooperative antiviral effects. In contrast, competitive effects were observed when using SP-D-sensitive strains. In addition to the viral strain, the sequence of incubation of a virus with $\alpha$-defensins or SP-D is responsible for different effects. These data indicate the complex interaction between SP-D and $\alpha$-defensins at sites of infections [56, 57]. SP-D has also been shown to play important roles in neutrophil extracellular trap-mediated bacterial trapping [59]. Neutrophils generate DNA-based extracellular traps to capture and kill microbes. SP-D binds both the traps and microbial surfaces resulting in promotion of bacterial trapping. These findings suggest that SP-D plays important roles in neutrophils-mediated host defense against microbes.

\section{Perspectives}

Both in vivo and in vitro studies have indicated the critical roles of pulmonary collectins in host defense and maintenance of homeostasis. Consistent with these results, several human diseases have been reported to be associated with polymorphisms in genes encoding pulmonary collectins and concentrations of collectins in BALF or serum [60]. In animal model, intratracheal administration of recombinant pulmonary collectins results in enhanced clearance of microbes and regulation of inflammatory responses, suggesting the possible usage of lung collectins as the basis of therapeutic strategies. To date, a variety of functional recombinant proteins including full-length proteins, C-terminal fragments, and chimeric proteins have been prepared to characterize the functions of pulmonary collectins. These recombinant proteins are also candidates as therapeutic reagents. For example, replacement of pulmonary collectins might be useful to inhibit the growth of intracellular pathogens and eliminate them, although detailed molecular basis of the inhibition should be clarified. Moreover, information about functions of pulmonary collectins in physiological conditions, especially concerning interactions with other innate immune molecules, should be accumulated to further advance the possibility that collectins play roles as therapeutic reagents.

\section{References}

[1] J. A. Hoffmann, F. C. Kafatos, C. A. Janeway, and R. A. B. Ezekowitz, "Phylogenetic perspectives in innate immunity," Science, vol. 284, no. 5418, pp. 1313-1318, 1999.

[2] R. J. King and J. A. Clements, "Surface active materials from dog lung. I. Method of isolation," The American Journal of Physiology, vol. 223, no. 3, pp. 707-714, 1972.

[3] R. Veldhuizen, K. Nag, S. Orgeig, and F. Possmayer, "The role of lipids in pulmonary surfactant," Biochimica et Biophysica Acta, vol. 1408, no. 2-3, pp. 90-108, 1998.

[4] K. Kuronuma, H. Mitsuzawa, K. Takeda et al., "Anionic pulmonary surfactant phospholipids inhibit inflammatory responses from alveolar macrophages and U937 cells by binding the lipopolysaccharide-interacting proteins CD14 and MD-2," Journal of Biological Chemistry, vol. 284, no. 38, pp. 2548825500, 2009.

[5] J. A. Whitsett and T. E. Weaver, "Hydrophobic surfactant proteins in lung function and disease," New England Journal of Medicine, vol. 347, no. 26, pp. 2141-2148, 2002.

[6] M. Yamazoe, C. Nishitani, M. Takahashi et al., "Pulmonary surfactant protein D inhibits lipopolysaccharide (LPS)induced inflammatory cell responses by altering LPS binding to its receptors," Journal of Biological Chemistry, vol. 283, no. 51, pp. 35878-35888, 2008.

[7] T. R. Korfhagen, M. D. Bruno, G. F. Ross et al., "Altered surfactant function and structure in SP-A gene targeted mice," Proceedings of the National Academy of Sciences of the United States of America, vol. 93, no. 18, pp. 9594-9599, 1996.

[8] T. R. Korfhagen, V. Sheftelyevich, M. S. Burhans et al., "Surfactant protein-D regulates surfactant phospholipid homeostasis 
in vivo," Journal of Biological Chemistry, vol. 273, no. 43, pp. 28438-28443, 1998.

[9] S. E. Wert, M. Yoshida, A. M. LeVine et al., "Increased metalloproteinase activity, oxidant production, and emphysema in surfactant protein D gene-inactivated mice," Proceedings of the National Academy of Sciences of the United States of America, vol. 97, no. 11, pp. 5972-5977, 2000.

[10] A. M. LeVine, K. E. Kurak, M. D. Bruno, J. M. Stark, J. A. Whitsett, and T. R. Korfhagen, "Surfactant protein-A-deficient mice are susceptible to Pseudomonas aeruginosa infection," American Journal of Respiratory Cell and Molecular Biology, vol. 19, no. 4, pp. 700-708, 1998.

[11] E. Giannoni, T. Sawa, L. Allen, J. Wiener-Kronish, and S. Hawgood, "Surfactant proteins A and D enhance pulmonary clearance of Pseudomonas aeruginosa," American Journal of Respiratory Cell and Molecular Biology, vol. 34, no. 6, pp. 704710, 2006.

[12] J. Hickman-Davis, J. Gibbs-Erwin, J. R. Lindsey, and S. Matalon, "Surfactant protein a mediates mycoplasmacidal activity of alveolar macrophages by production of peroxynitrite," Proceedings of the National Academy of Sciences of the United States of America, vol. 96, no. 9, pp. 4953-4958, 1999.

[13] E. N. Atochina, A. J. Gow, J. M. Beck et al., "Delayed clearance of Pneumocystis carinii infection, increased inflammation, and altered nitric oxide metabolism in lungs of surfactant proteinD knockout mice," Journal of Infectious Diseases, vol. 189, no. 8, pp. 1528-1539, 2004.

[14] F. X. McCormack, R. Gibbons, S. R. Ward, A. Kuzmenko, H. $\mathrm{Wu}$, and G. S. Deepe, "Macrophage-independent fungicidal action of the pulmonary collectins," Journal of Biological Chemistry, vol. 278, no. 38, pp. 36250-36256, 2003.

[15] A. M. LeVine, J. A. Whitsett, J. A. Gwozdz et al., "Distinct effects of surfactant protein A or D deficiency during bacterial infection on the lung," Journal of Immunology, vol. 165, no. 7, pp. 3934-3940, 2000.

[16] A. M. Levine, M. D. Bruno, K. M. Huelsman, G. F. Ross, J. A. Whitsett, and T. R. Korfhagen, "Surfactant protein A-deficient mice are susceptible to group B streptococcal infection," Journal of Immunology, vol. 158, no. 9, pp. 4336-4340, 1997.

[17] A. M. LeVine, J. Gwozdz, J. Stark, M. Bruno, J. Whitsett, and T. Korfhagen, "Surfactant protein-A enhances respiratory syncytial virus clearance in vivo," Journal of Clinical Investigation, vol. 103, no. 7, pp. 1015-1021, 1999.

[18] A. M. LeVine, J. Elliott, J. A. Whitsett et al., "Surfactant protein-D enhances phagocytosis and pulmonary clearance of respiratory syncytial virus," American Journal of Respiratory Cell and Molecular Biology, vol. 31, no. 2, pp. 193-199, 2004.

[19] G. Li, J. Siddiqui, M. Hendry et al., "Surfactant protein-A-deficient mice display an exaggerated early inflammatory response to a $\beta$-resistant strain of influenza A virus," American Journal of Respiratory Cell and Molecular Biology, vol. 26, no. 3, pp. 277-282, 2002.

[20] A. M. LeVine, K. Hartshorn, J. Elliott, J. Whitsett, and T. Korfhagen, "Absence of SP-A modulates innate and adaptive defense responses to pulmonary influenza infection," American Journal of Physiology, vol. 282, no. 3, pp. L563-L572, 2002.

[21] A. Hogenkamp, M. van Eijk, and H. P. Haagsman, "Collectins-interaction with pathogens," in Collargen-Related Lectins in Innate Immunity, D. Kilpatrick, Ed., pp. 119-177, Research Signpost, Kerala, India, 2007.

[22] H. Sano, H. Sohma, T. Muta, S. I. Nomura, D. R. Voelker, and Y. Kuroki, "Pulmonary surfactant protein a modulates the cellular response to smooth and rough lipopolysaccharides by interaction with CD14," Journal of Immunology, vol. 163, no. 1, pp. 387-395, 1999.

[23] J. F. van Iwaarden, J. C. Pikaar, J. Storm et al., "Binding of surfactant protein A to the lipid A moiety of bacterial lipopolysaccharides," Biochemical Journal, vol. 303, no. 2, pp. 407411, 1994.

[24] S. F. Kuan, K. Rust, and E. Crouch, "Interactions of surfactant protein D with bacterial lipopolysaccharides. Surfactant protein D is an Escherichia coli-binding protein in bronchoalveolar lavage," Journal of Clinical Investigation, vol. 90, no. 1, pp. 97-106, 1992.

[25] H. Sahly, I. Ofek, R. Podschun et al., "Surfactant protein D binds selectively to Klebsiella pneumoniae lipopolysaccharides containing mannose-rich O-antigens," Journal of Immunology, vol. 169, no. 6, pp. 3267-3274, 2002.

[26] J. F. Head, T. R. Mealy, F. X. McCormack, and B. A. Seaton, "Crystal structure of trimeric carbohydrate recognition and neck domains of surfactant protein A," Journal of Biological Chemistry, vol. 278, no. 44, pp. 43254-43260, 2003.

[27] S. Ariki, T. Kojima, S. Gasa et al., "Pulmonary collectins play distinct roles in host defense against Mycobacterium avium," The Journal of Immunology, vol. 187, no. 5, pp. 2586-2594, 2011.

[28] H. Wu, A. Kuzmenko, S. Wan et al., "Surfactant proteins A and $\mathrm{D}$ inhibit the growth of Gram-negative bacteria by increasing membrane permeability," Journal of Clinical Investigation, vol. 111, no. 10, pp. 1589-1602, 2003.

[29] M. F. Geertsma, P. H. Nibbering, H. P. Haagsman, M. R. Daha, and R. Van Furth, "Binding of surfactant protein A to C1q receptors mediates phagocytosis of Staphylococcus aureus by monocytes," American Journal of Physiology, vol. 267, no. 5, pp. L578-L584, 1994.

[30] Z. Sever-Chroneos, A. Krupa, J. Davis et al., "Surfactant protein A (SP-A)-mediated clearance of Staphylococcus aureus involves binding of SP-A to the staphylococcal adhesin Eap and the macrophage receptors SP-A receptor 210 and scavenger receptor class A," Journal of Biological Chemistry, vol. 286, no. 6, pp. 4854-4870, 2011.

[31] L. F. Weikert, K. Edwards, Z. C. Chroneos, C. Hager, L. Hoffman, and V. L. Shepherd, "SP-A enhances uptake of bacillus Calmette-Guerin by macrophages through a specific SP-A receptor," American Journal of Physiology, vol. 272, no. 5, pp. L989-L995, 1997.

[32] Z. C. Chroneos, R. Abdolrasulnia, J. A. Whitsett, W. R. Rice, and V. L. Shepherd, "Purification of a cell-surface receptor for surfactant protein A," Journal of Biological Chemistry, vol. 271, no. 27, pp. 16375-16383, 1996.

[33] W. I. Mariencheck, J. Savov, Q. Dong, M. J. Tino, and J. R. Wright, "Surfactant protein A enhances alveolar macrophage phagocytosis of a live, mucoid strain of P. aeruginosa," American Journal of Physiology, vol. 277, no. 4, pp. L777-L786, 1999.

[34] C. I. Restrepo, Q. Dong, J. Savov, W. I. Mariencheck, and J. R. Wright, "Surfactant protein D stimulates phagocytosis of Pseudomonas aeruginosa by alveolar macrophages," American Journal of Respiratory Cell and Molecular Biology, vol. 21, no. 5, pp. 576-585, 1999.

[35] W. I. Mariencheck, J. F. Alcorn, S. M. Palmer, and J. R. Wright, "Pseudomonas aeruginosa elastase degrades surfactant proteins A and D," American Journal of Respiratory Cell and Molecular Biology, vol. 28, no. 4, pp. 528-537, 2003.

[36] Z. Kuang, Y. Hao, B. E. Walling et al., "Pseudomonas aeruginosa elastase provides an escape from phagocytosis by degrading the pulmonary surfactant protein-A," PLoS One, vol. 6, no. 11, p. e27091, 2011. 
[37] K. Kuronuma, H. Sano, K. Kato et al., "Pulmonary surfactant protein A augments the phagocytosis of Streptococcus pneumoniae by alveolar macrophages through a casein kinase 2-dependent increase of cell surface localization of scavenger receptor A," Journal of Biological Chemistry, vol. 279, no. 20, pp. 21421-21430, 2004.

[38] K. Kudo, H. Sano, H. Takahashi et al., "Pulmonary collectins enhance phagocytosis of Mycobacterium avium through increased activity of mannose receptor," Journal of Immunology, vol. 172, no. 12, pp. 7592-7602, 2004.

[39] A. A. Beharka, C. D. Gaynor, B. K. Kang, D. R. Voelker, F. X. McCormack, and L. S. Schlesinger, "Pulmonary surfactant protein a up-regulates activity of the mannose receptor, a pattern recognition receptor expressed on human macrophages," Journal of Immunology, vol. 169, no. 7, pp. 3565-3573, 2002.

[40] A. J. Tenner, S. L. Robinson, J. Borchelt, and J. R. Wright, "Human pulmonary surfactant protein (SP-A), a protein structurally homologous to C1q, can enhance FcR- and CR1mediated phagocytosis," Journal of Biological Chemistry, vol. 264, no. 23, pp. 13923-13928, 1989.

[41] T. L. Schagat, J. A. Wofford, and J. R. Wright, "Surfactant protein a enhances alveolar macrophage phagocytosis of apoptotic neutrophils," Journal of Immunology, vol. 166, no. 4, pp. 2727-2733, 2001.

[42] J. H. Fisher, P. M. Henson, K. E. Greene et al., "Role of surfactant proteins A, D, and C1q in the clearance of apoptotic cells in vivo and in vitro: calreticulin and CD91 as a common collectin receptor complex," Journal of Immunology, vol. 169, no. 7, pp. 3978-3986, 2002.

[43] W. J. Janssen, K. A. McPhillips, M. G. Dickinson et al., "Surfactant proteins A and D suppress alveolar macrophage phagocytosis via interaction with $\operatorname{SIRP} \alpha$," American Journal of Respiratory and Critical Care Medicine, vol. 178, no. 2, pp. 158$167,2008$.

[44] K. Sawada, S. Ariki, T. Kojima et al., "Pulmonary collectins protect macrophages against pore-forming activity of Legionella pneumophila and suppress its intracellular growth," Journal of Biological Chemistry, vol. 285, no. 11, pp. 8434-8443, 2010.

[45] J. S. Ferguson, J. L. Martin, A. K. Azad et al., "Surfactant protein D increases fusion of Mycobacterium tuberculosis- containing phagosomes with lysosomes in human macrophages," Infection and Immunity, vol. 74, no. 12, pp. 7005-7009, 2006.

[46] J. R. Wright, "Immunoregulatory functions of surfactant proteins," Nature Reviews Immunology, vol. 5, no. 1, pp. 58-68, 2005.

[47] Y. Kuroki, M. Takahashi, and C. Nishitani, "Pulmonary collectins in innate immunity of the lung," Cellular Microbiology, vol. 9, no. 8, pp. 1871-1879, 2007.

[48] S. Murakami, D. Iwaki, H. Mitsuzawa et al., "The extracellular toll-like receptor 2 domain directly binds peptidoglycan derived from Staphylococcus aureus," Journal of Biological Chemistry, vol. 277, no. 27, pp. 24315-24320, 2002.

[49] M. Sato, H. Sano, D. Iwaki et al., "Direct binding of toll-like receptor 2 to Zymosan, and Zymosan-induced NF- $\kappa$ B activation and TNF- $\alpha$ secretion are down-regulated by lung collectin surfactant protein A," Journal of Immunology, vol. 171, no. 1, pp. 417-425, 2003.

[50] C. Yamada, H. Sano, T. Shimizu et al., "Surfactant protein A directly interacts with TLR4 and MD-2 and regulates inflammatory cellular response: importance of supratrimeric oligomerization," Journal of Biological Chemistry, vol. 281, no. 31, pp. 21771-21780, 2006.
[51] M. Ohya, C. Nishitani, H. Sano et al., "Human pulmonary surfactant protein D binds the extracellular domains of Tolllike receptors 2 and 4 through the carbohydrate recognition domain by a mechanism different from its binding to phosphatidylinositol and lipopolysaccharide," Biochemistry, vol. 45, no. 28, pp. 8657-8664, 2006.

[52] X. Nie, C. Nishitani, M. Yamazoe et al., "Pulmonary surfactant protein $\mathrm{D}$ binds MD-2 through the carbohydrate recognition domain," Biochemistry, vol. 47, no. 48, pp. 12878-12885, 2008.

[53] M. Yamazoe, C. Nishitani, M. Takahashi et al., "Pulmonary surfactant protein D inhibits lipopolysaccharide (LPS)induced inflammatory cell responses by altering LPS binding to its receptors," Journal of Biological Chemistry, vol. 283, no. 51, pp. 35878-35888, 2008.

[54] S. J. Gardai, Y. Q. Xiao, M. Dickinson et al., "By binding SIRP $\alpha$ or calreticulin/CD91, lung collectins act as dual function surveillance molecules to suppress or enhance inflammation," Cell, vol. 115, no. 1, pp. 13-23, 2003.

[55] C. J. Guo, E. N. Atochina-Vasserman, E. Abramova et al., "Snitrosylation of surfactant protein-D controls inflammatory function.," PLoS biology, vol. 6, no. 11, p. e266, 2008.

[56] K. L. Hartshorn, M. R. White, T. Tecle, U. Holmskov, and E. C. Crouch, "Innate defense against influenza A virus: activity of human neutrophil defensins and interactions of defensins with surfactant protein D," Journal of Immunology, vol. 176, no. 11, pp. 6962-6972, 2006.

[57] M. Doss, M. R. White, T. Tecle et al., "Interactions of alpha-, beta-, and theta-defensins with influenza A virus and surfactant protein D," The Journal of Immunology, vol. 182, no. 12, pp. 7878-7887, 2009.

[58] E. R. Job, Y. M. Deng, M. D. Tate et al., "Pandemic H1N1 influenza a viruses are resistant to the antiviral activities of innate immune proteins of the collectin and pentraxin superfamilies," Journal of Immunology, vol. 185, no. 7, pp. 42844291, 2010.

[59] D. N. Douda, R. Jackson, H. Grasemann et al., "Innate immune collectin surfactant protein D simultaneously binds both neutrophil extracellular traps and carbohydrate ligands and promotes bacterial trapping," The Journal of Immunology, vol. 187, no. 4, pp. 1856-1865, 2011.

[60] G. L. Sorensen, S. Husby, and U. Holmskov, "Surfactant protein $\mathrm{A}$ and surfactant protein $\mathrm{D}$ variation in pulmonary disease," Immunobiology, vol. 212, no. 4-5, pp. 381-416, 2007. 

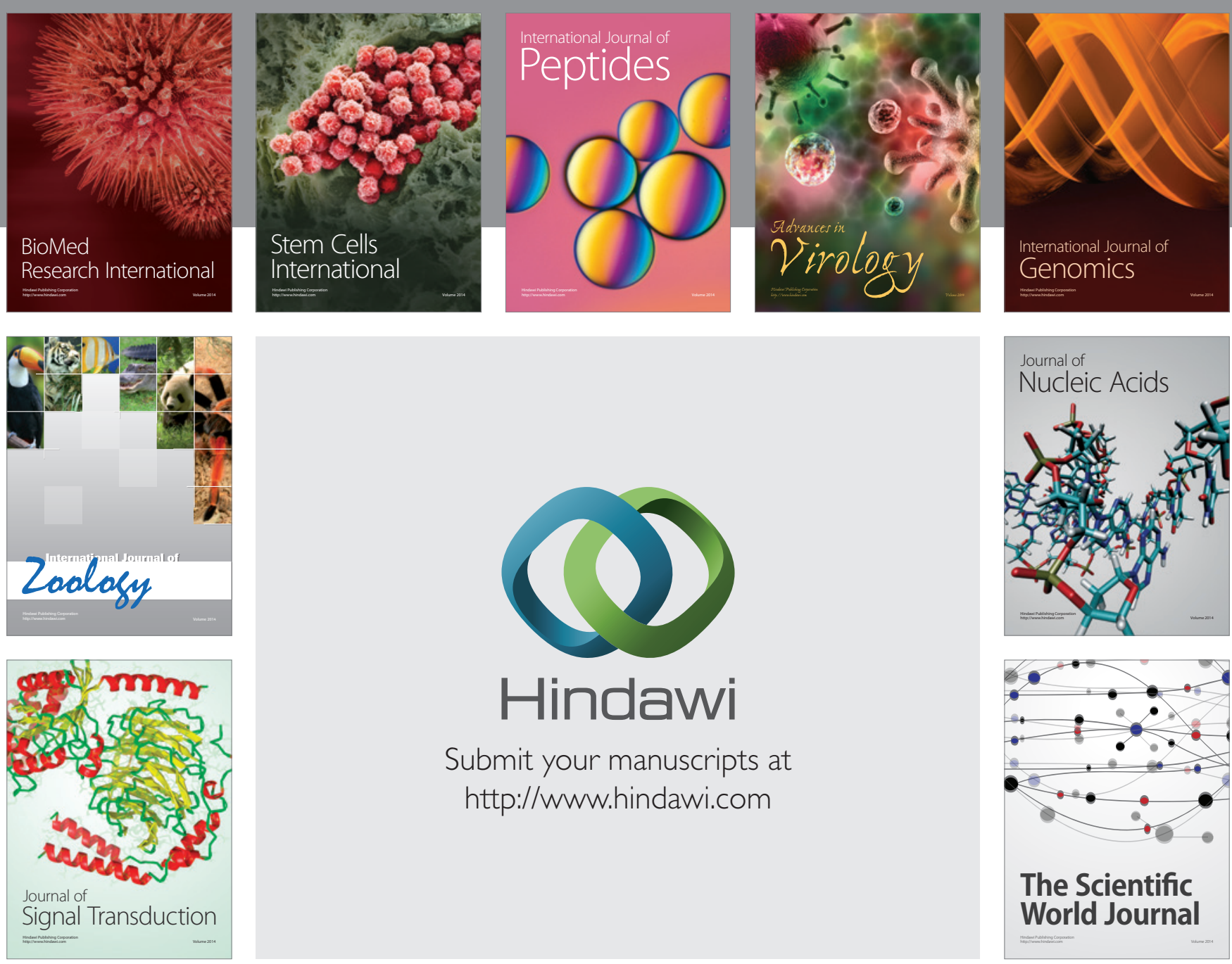

Submit your manuscripts at

http://www.hindawi.com
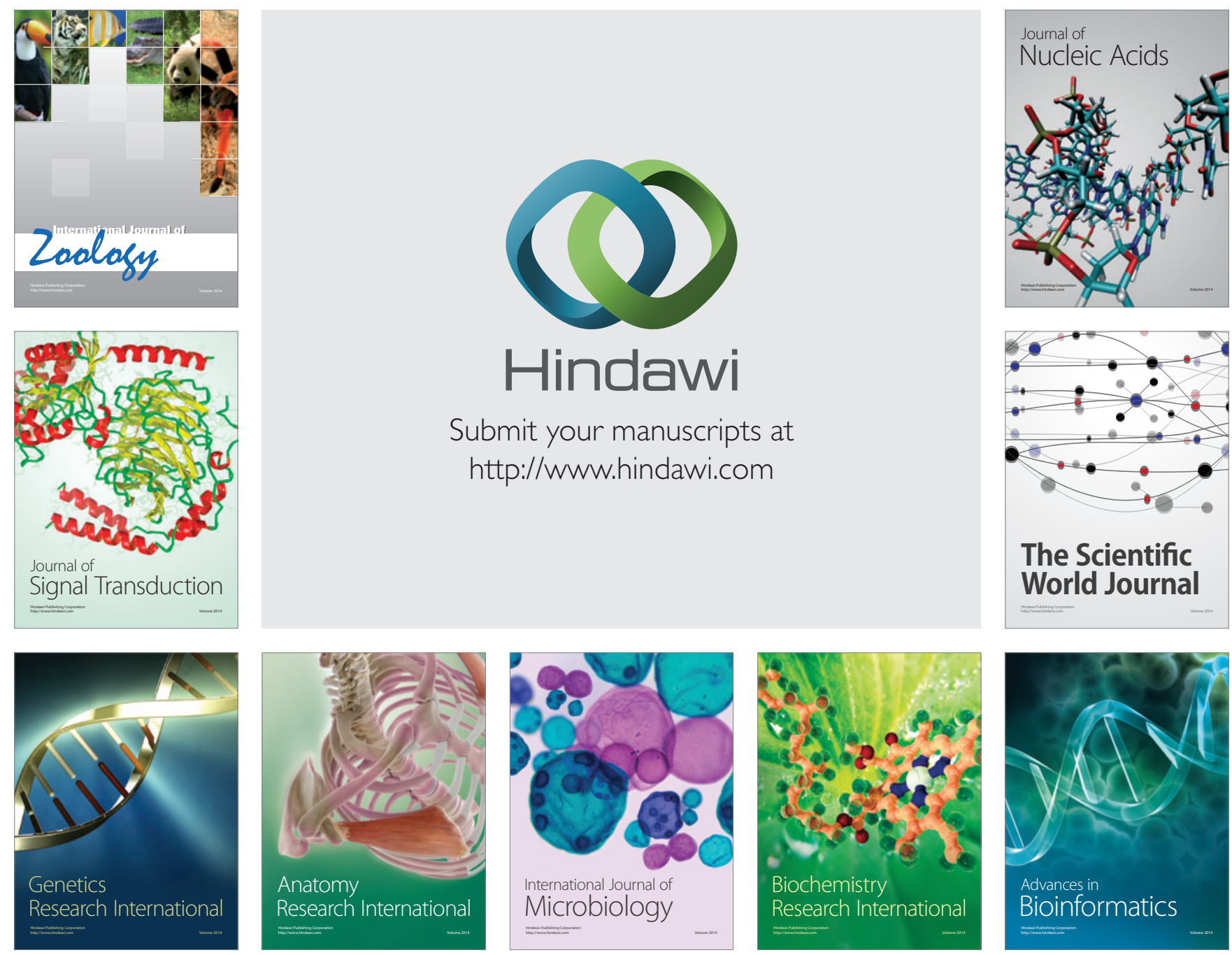

The Scientific World Journal
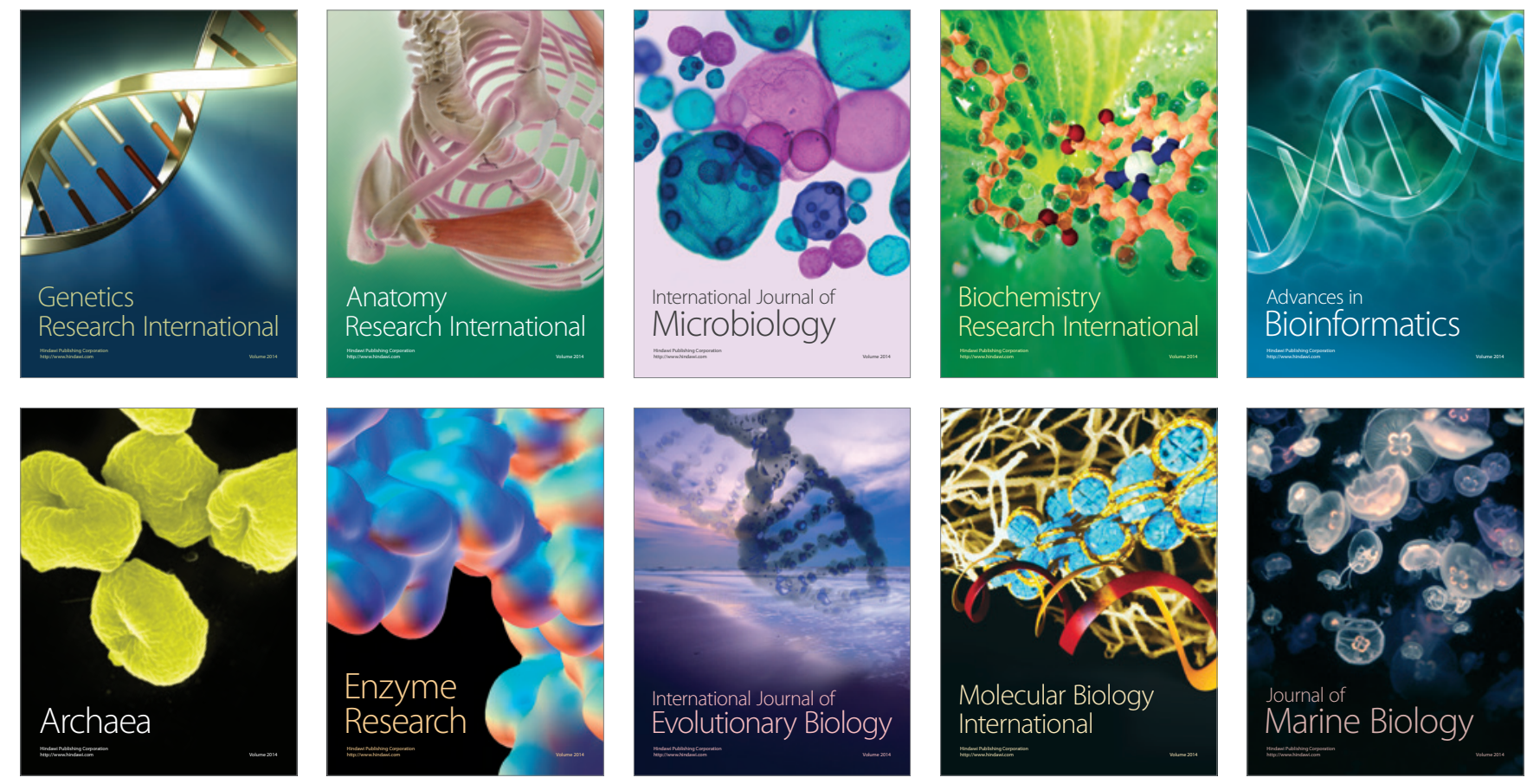